\title{
Addressing physician quality of life: understanding the relationship between burnout, work engagement, compassion fatigue and satisfaction
}

\author{
Angelina OM Chan ${ }^{* 1}$, Yiong Huak Chan ${ }^{2}$, Kee Puay Chuang ${ }^{1}$, Joyce SC Ng${ }^{1}$, Patricia SH Neo ${ }^{3}$ \\ ${ }^{1}$ Trauma Recovery \& Corporate Solutions, Changi General Hospital, Singapore \\ ${ }^{2}$ Biostatistics Unit, Yong Loo Lin School of Medicine, National University Health Systems, Singapore \\ ${ }^{3}$ Department of Palliative Medicine, National Cancer Centre, Singapore
}

Received: July 8, 2015

DOI: $10.5430 /$ jha.v4n6p46
Accepted: August 19, 2015

Online Published: August 24, 2015

\begin{abstract}
Burnout and compassion fatigue are now recognized as occupational hazards associated with the medical profession. Interestingly, burnout and compassion fatigue do not occur in every physician and many continue to find joy, meaning and satisfaction in their work despite its challenges and stressors. Our study looked at the relationship between burnout, work engagement, compassion fatigue and satisfaction amongst doctors. We also studied the relationship between these and four measureable intrinsic human factors; self-efficacy, resilient personality type, sense of gratitude and work calling. Our study found that $37 \%$ of the doctors were at high risk of burnout and $7.5 \%$ were at high risk of compassion fatigue and only $3.3 \%$ and $1.5 \%$ were at low risk of burnout and compassion fatigue respectively. Only $2.7 \%$ and $0.3 \%$ had high rates of work engagement and compassion satisfaction respectively. There was a mild but significant negative correlation between burnout and engagement, and a poor negative correlation between compassion fatigue and satisfaction. Only intrinsic human factors were significantly correlated to burnout, work engagement, compassion fatigue and satisfaction. Our preliminary findings suggest that certain intrinsic factors increase work engagement and compassion satisfaction amongst doctors. As some of these intrinsic factors also appear to buffer against burnout and compassion fatigue, increasing work engagement and compassion satisfaction not only builds individual resilience against burnout and compassion fatigue but may also lead to improvement in overall health, professional quality of life and career longevity for doctors.
\end{abstract}

Key Words: Burnout, Engagement, Compassion fatigue, Satisfaction, Resilience

\section{INTRODUCTION}

The increasing use of technology and ever-rising patient demands has changed the practice of medicine. Together they have intensified the physical and emotional impact of care-giving among doctors. Burnout and compassion fatigue are now recognized as occupational hazards associated with the medical profession. ${ }^{[1]}$ Hence it is not surprising that physician burnout rates are high, ranging from $30 \%$ to $70 \% .^{[1,2]}$ Of concern is how burnout and compassion fatigue can aggravate physician mental health. Research show that prevalence rates of psychiatric morbidity among doctors range between $15 \%$ to $35 \%{ }^{[2-4]}$ with some studies sug-

*Correspondence: Angelina OM Chan; Email: angelina_chan@cgh.com.sg; Address: Trauma Recovery \& Corporate Solutions, Changi General Hospital, 2 Simei Street, 529889, Singapore. 
gesting that burnout may be associated with depression. ${ }^{[5,6]}$ Apart from the direct mental health impact to the doctor, burnout and compassion fatigue are also associated with increased rates of medical errors, malpractice risk, physician turnover and hence increased healthcare manpower costs. ${ }^{[7,8]}$ In addition, emerging research suggests physician burnout to be a chronic condition rather than a transient one with only about a third recovering fully from severe burnout after 5-10 years. ${ }^{[9]}$ These have important implications on the overall mental health of doctors, their ability to function optimally at work as well as career longevity. Hence there is an urgent need to identify factors that can help prevent and/or moderate the development of burnout and compassion fatigue.

Burnout is defined as physical, emotional and mental exhaustion caused by prolonged high workload, sense of powerless or lack of control, ${ }^{[10]}$ as well as with certain personality factors such as perfectionism, compulsiveness, self-denial. ${ }^{[1-13]}$ Maslach and Leiter ${ }^{[13]}$ later rephrased burnout as "an erosion of engagement with the job". So what started as important, meaningful and challenging work became unpleasant, unfulfilling and meaningless. Energy turned into exhaustion, involvement turned into cynicism and efficacy turned into ineffectiveness. Accordingly, work engagement is characterized by energy, involvement and efficacy, the opposite of burnout.

Schaufeli and Bakker defined work engagement as "an active, positive work-related state characterized by vigor, dedication and absorption". ${ }^{[14]}$ Vigor refers to high levels of energy and mental resilience while working whereas Dedication refers to being strongly involved in one's work and experiencing a sense of significance, enthusiasm and challenge. Absorption is characterized by being fully concentrated and happily engrossed in work such that time passes quickly. Thus work engagement is characterized by a high level of energy and strong identification with one's work whereas burnout is characterized by the opposite, a low level of energy and poor identification with one's work. The consequences of burnout are poor mental and physical health ${ }^{[15,16]}$ as well as negative job performance, while studies have linked work engagement to better overall health, ${ }^{[17]}$ better job performance, organizational citizenship behaviours $^{[18]}$ as well as organizational performance. ${ }^{[19]}$ Although there are varying views regarding the dimensionality of burnout and engagement, it does appear that increasing work engagement may help to mitigate the negative impact of burnout.

In recent times, there have been a growing number of research publications on burnout among physicians in specific disciplines such as residents, oncology, palliative medicine and general practitioners. These have focused mainly on

Published by Sciedu Press the extrinsic/environmental factors such as increasing workload and working hours, demanding patients, working with terminally ill or trauma patients, family-work conflicts, violence at work etc as risk factors. ${ }^{[20,21]}$ Literature looking at work engagement and the relationship between burnout and work engagement among doctors is extremely limited. Understanding the relationship between burnout and work engagement among doctors, may enable healthcare institutions to develop targeted interventions that help prevent and/or moderate burnout while increasing work engagement which can improve the emotional and physical health of doctors as well as their career longevity.

Compassion fatigue was first coined by Joinson as "the profound emotional and physical exhaustion that helping professionals and caregivers can develop over time as a result of repeated exposure to the suffering during their work". ${ }^{[22]}$ Compassion fatigue is also known as secondary traumatic stress and is related to vicarious traumatization among professional caregivers who care for patients with posttraumatic stress disorder and those suffering in general. ${ }^{[23,24]}$ In contrast, Stamm defined compassion satisfaction as the "sense of pleasure derived from doing the job well, helping others or any other form of contribution to the work". [25] Compassion satisfaction has been posited to be a protective factor that buffers the potentially negative consequences of exposure to traumatic events and subsequent burnout. ${ }^{[26]}$ Factors associated with compassion fatigue among doctors include working with trauma survivors, past personal history of traumatic events, lack of support systems, lack of experience, poor work and personal life balance, and lack of self-awareness. ${ }^{[27]}$ Although there is an abundance of literature on burnout, there is much less on compassion fatigue and extremely little on compassion satisfaction. Even fewer studies look at the relationships between compassion satisfaction and compassion fatigue in healthcare. Understanding the relationship between compassion fatigue and compassion satisfaction may help improve the quality of professional life of doctors as well as care to patients and their families.

Interestingly, burnout and compassion fatigue do not occur in every doctor and many continue to find joy, meaning and satisfaction in their work despite its many challenges and stressors. ${ }^{[28]}$ This suggest that some doctors possess certain intrinsic human/personality factors rendering them more resilient to environmental/extrinsic stressors with subsequent protection against burnout and compassion fatigue compared to others in similar work environments. This observation appears to be supported by the findings of Alarcon and colleagues $^{[29]}$ who postulated that people with higher scores on self-esteem, self-efficacy, locus of control, positive affectivity, optimism, proactive personality and hardiness, are better 
able to cope with their job demands. Identifying and understanding the intrinsic human factors that positively impact on burnout and compassion fatigue among doctors would enable the development of specific interventions. To date, there has been very little research in this area.

Our aims are to understand, firstly, the relationships between burnout, work engagement, compassion fatigue and compassion satisfaction, and, secondly, the relationships between four measurable intrinsic human factors and burnout, work engagement, compassion fatigue and compassion satisfaction. By understanding these relationships, we hope to eventually enhance individual resilience in doctors against burnout and compassion fatigue through the development of training programs based on identified and measurable intrinsic human factors that limit burnout and compassion fatigue and increase work engagement and compassion satisfaction.

\section{METHOD}

\subsection{Participants}

This paper is based on a two-centre, cross-sectional study on burnout, compassion fatigue, compassion satisfaction, work engagement among doctors working in Singapore at an acute public general hospital and a public specialist oncology centre. The survey was administered in English and consisted of self-report questionnaires with the purpose of the study stated on the front cover. The survey response was strictly confidential and anonymous. The data collection took place from Jan to Apr 2015. At the time of the survey, there were no external or environmental factors such as building construction, or internal factors such as disruption of workflow or working conditions, departmental Head changes etc. at either of the centres surveyed. Ethics approval for this study was obtained from the Singhealth Institutional Research Board.

\subsection{Sampling procedure}

We used a convenience sample and recruited doctors from the following disciplines: Emergency Medicine, Radiology, Gastroenterology, Respiratory Medicine, Geriatric Medicine, General Surgery, Orthopaedics, Anaesthesiology, Palliative Medicine, Medical Oncology, Surgical Oncology and Radiation Oncology. With the support of the respective Head of Departments, we explained the purpose of the study and invited doctors who were present at their Departmental meetings and invited them to participate. For five Departments, the study questionnaires were sent to the Departments at the request of their Heads of Departments instead. Participation was voluntary and their responses anonymous. Return of completed questionnaires was considered informed consent to participate in this study. The overall response rate was $332 / 358$.

\subsection{Measures}

We collected doctor characteristics like age, sex, marital status, religion, ethnicity, job title, average number of hours per week spent on work-related activities, years of working experience in healthcare, years of experience working mainly with terminally ill.

Burnout and Compassion Satisfaction were measured using the ProQOL-R-IV subscale for burnout and compassion satisfaction. ${ }^{[25]}$ It comprised of 10 statements corresponding to each subscale and is scored on a 6-point Likert scale, ranging from "never" to "very often". Cut scores based on the $75^{\text {th }}$ percentile indicate relative risks or protective factors. The average score on the burnout scale is $22(S D=6$; alpha scale reliability $=0.72$ ). A score below 17 indicates low risk, between 17 and 28 a moderate risk and scores above 28 indicate a high risk for burnout. The average score on the compassion satisfaction subscale 37 ( $S D=7$; alpha scale reliability $=0.87$ ). Scores below 32 indicate low potential for compassion satisfaction, scores between 32 and 41 represent moderate potential, and scores above 41 indicate high potential.

The UWES-9 ${ }^{[30]}$ was used to measure the 3 core dimensions of work engagement: Vigor, Dedication, and Absorption. The internal consistency of UWES- 9 is above 0.80 with the latent variables Vigor, Dedication, and Absorption strongly intercorrelated (mean $r=0.92$ ). This scale comprises 9 statements with 3 items for each subscale. All items are scored on a 6-point Likert scale ranging from 0 (never) to 6 (always). For each subscale, the scores are averaged. A total score of 4 and above indicate work engagement.

Compassion fatigue was measured using the Silencing Response Scale (SRS). ${ }^{[31]}$ Silencing response (SR) or active avoidance is a component of compassion fatigue. This response can be either an indication of experience of compassion fatigue or an attempt to avoid the negative effect associated with compassion fatigue. It refers to the inability of caregivers to pay attention to the stories or experiences of their patients and the tendency to direct the conversation rather to less distressing material. SR occurs when patient's experiences are overwhelming, beyond the caregiver's scope of comprehension and desire to know, or simply spirals past the helper's sense of competency. SRS correlates positively with compassion fatigue subscale of ProQOL-R-IV and exhibits internal reliability with an alpha co-efficient of 0.69 and a split-half reliability of $0.63 .{ }^{[32]}$ The scale comprises of 15 statements and is scored on a 10-point Likert scale ranging from "rarely/never" to "always". Scores between 0 and 20 indicate minimal risk for the activation of the SR or compassion fatigue, while those between 21 and 40 indicate 
some risk. Scores between 41 and 94 indicate moderate risk and those from 95 to 150 represent high risk.

To measure intrinsic human factors, we used the following self-report questionnaires for self-efficacy, resilient personality type, sense of gratitude and work calling:

(1) General Self-Efficacy Scale (GSE) was created to assess a general sense of perceived self-efficacy with the aim to predict coping with daily hassles and adaptation after experiencing all kinds of stressful life events. ${ }^{[33]}$ The construct of perceived self-efficacy reflects an optimistic self-belief. This is the belief that one can perform a novel or difficult tasks, or cope with adversity in various domains of human functioning. Perceived self-efficacy facilitates goal-setting, effort investment, persistence in face of barriers and recovery from setbacks. It can be regarded as a positive resistance resource factor. Ten items are designed to tap this construct. Each item refers to successful coping and implies an internal-stable attribution of success. Perceived self-efficacy is an operative construct, i.e. it is related to subsequent behavior and therefore is relevant for clinical practice and behavior change. In samples from 23 nations, Cronbach's alphas ranged from 0.76 to 0.90 , with the majority in the high 0.80 . The scale is unidimensional. It consists of 10 items and is scored on a Likert 4-point scale ranging from "not at all true" to "exactly true" with the final composite score ranging from 10 to 40 . We chose a median split with a cut-off of 30 . Hence a score between 0 and 29 is low while 30 to 40 high.

(2) Ego Resiliency Scale (ER89) was used to measure the resilient personality type. ${ }^{[34]}$ Ego-resiliency (ER) describes the ability to respond flexibly to situational demands such as acute stress, conflicts or uncertainty and conceptually, it is related to the constructs of competence, social intelligence and coping. High levels of ER characterize the resilient type with faster psychological and emotional recovery from stress while individual with low levels possess fewer adaptive capabilities and are thus more likely to respond unfavourably to various environmental stressors. The ER89 has 14 items scored on a 4-point Likert scale from " 1 = does not apply at all" to " $4=$ applies very strongly" and its validity has been established. ${ }^{[35]}$ The scores between the range 20 to 38 indicate low ER, 39 to 42 average and 43-56 above average.

(3) GQ-6 $6^{[36]}$ is a short, self-report measure of the disposition to experience gratitude. There are 6 items on a 7-point Likert scale ranging from "strongly disagree" to "strongly agree". GQ-6 has good internal reliability, with alphas between 0.82 and 0.87 . GQ-6 is positively related to optimism, life satisfaction, hope, spirituality and religiousness, forgiveness, empathy and prosocial behaviour, and negatively related to depression, anxiety, materialism and envy. Scores ranging less than 35 indicate low gratitude, 35 to 40 average and greater than 40 high.

(4) Calling and vocation was measured using the Brief Calling Scale (BCS) developed by Dik and Steger. ${ }^{[37]}$ Calling was defined as a "person's belief that she/he is called to do a particular kind of work". The BCS consists of 4 items with two subscales; presence of calling ( 2 items) and search for calling ( 2 items). The responses are rated on a 5-point Likert scale ranging from "not at all true of me" to "totally true of $m e$ ". The correlation between the two items of BCSPresence was reported as $r=0.81$, and $r=0.75$ for BCS-Search items. The scores on the scale correlate in predicted directions and magnitudes with self-efficacy, outcome expectations, materialism, spirituality, and sense of calling assessed using the career development strivings strategy. ${ }^{[38]}$ Scores of 3 and less is low while more than 3 is high.

\subsection{Data analysis}

All statistical analyses were performed using STATA 13.0 with statistical significance set at $p<.05$. To account for the multi-colinearity of the measures (GSE, ER89, GQ-6, BCS-Presence \& BCS-Search) for predictions of low burnout or Minimal/Some compassion fatigue in a logistic regression model, moderate/high burnout, low work engagement, moderate/high compassion fatigue \& low compassion satisfaction adjusting for demographical characteristics of the participants, Principal Components (to have zero correlation amongst the scales) were developed for these measures. A one-factor Confirmatory Factor Analysis (CFA) on the latent variable Resilience was performed to determine which Extrinsic/Intrinsic variable has the highest impact.

\section{Results}

Table 1 shows the demographical results of the participants. Majority were Chinese (over 70\%), 55\% males, a quarter above 40 years of age and more than $60 \%$ from the Oncology Centre and Surgical Division. $40 \%$ were never married and $65 \%$ worked more than 50 hours per week. $65 \%$ of the participants had more than 5 years of working experience and $25 \%$ had at least 5 years of working with terminally ill patients. The mean $(S D)$, range of all the measure scales of the participants are also shown in Table 1. 
Table 1. Participants' demographical \& measures characteristics (Total $\mathrm{n}=332$ )

\begin{tabular}{|c|c|}
\hline Demographical variables & n (\%) \\
\hline \multicolumn{2}{|l|}{ Division } \\
\hline Ambulatory & $51(15.4)$ \\
\hline Medical & $61(18.4)$ \\
\hline Onco Centre & $91(27.4)$ \\
\hline Surgical & $129(38.9)$ \\
\hline \multicolumn{2}{|l|}{ Department } \\
\hline Accident \& Emergency & $34(10.2)$ \\
\hline Anaesthesia & $30(9.0)$ \\
\hline Diagnostic Radiology & $17(5.1)$ \\
\hline Gastroenterology & $8(2.4)$ \\
\hline General Surgery & $53(16.0)$ \\
\hline Geriatric Medicine & $35(10.5)$ \\
\hline Medical Oncology & $41(12.3)$ \\
\hline Orthopaedic Surgery & $46(13.9)$ \\
\hline Palliative Medicine & $18(5.4)$ \\
\hline Radiation Oncology & $28(8.4)$ \\
\hline Respiratory Medicine & $18(5.4)$ \\
\hline Surgical Oncology & $4(1.2)$ \\
\hline \multicolumn{2}{|l|}{ Gender (8 missing) } \\
\hline Female & $145(44.8)$ \\
\hline Male & $179(55.2)$ \\
\hline \multicolumn{2}{|l|}{ Ethnicity (4 missing) } \\
\hline Chinese & $241(73,5)$ \\
\hline Indian & 39 (11.9) \\
\hline Malay & $7(2.1)$ \\
\hline Others & $41(12.5)$ \\
\hline \multicolumn{2}{|l|}{ Information } \\
\hline Never Married & $141(42.5)$ \\
\hline Have a Religion & $67(20.2)$ \\
\hline Worked above 50 hours a week & $218(65.7)$ \\
\hline Work experience above 5 years & $216(65.1)$ \\
\hline Work with terminally ill more than 5 years & 85 (25.6) \\
\hline Age above 40 years old & $82(24.7)$ \\
\hline Measures & Mean (SD), range \\
\hline Burnout & $26.8(5.5), 11-44$ \\
\hline Utrecht Work Engagement Scale & $3.6(0.9), 0-6$ \\
\hline Compassion Fatigue & 63.4 (21.6), $11-136$ \\
\hline Compassion Satisfaction & $36.2(6.4), 15-50$ \\
\hline Ego Resiliency Total & 40.0 (6.2), $14-55$ \\
\hline General Self Efficacy Total & $30.0(3.7), 10-40$ \\
\hline GQ-6 Total & $33.5(6.0), 6-42$ \\
\hline Brief Calling-Presence Total & $7.0(2.1), 2-10$ \\
\hline Brief Calling-Search Total & $5.0(2.3), 2-10$ \\
\hline
\end{tabular}

Upon univariate analyses of the demographical variables on the outcome of interests, the following were observed:

- Compassion Fatigue: Race (Chinese 90\%, Malay $85.7 \%$, Indian $72.2 \%$, Others $78.9 \%, p=.014)$, Work experience > 5 years ("no" $92.2 \%$, "yes" $82.7 \%$, $p=.017$ ), Age above 40 years ("no" 89.7\%, "yes" $75.3 \%, p=.001$ ), Work with terminally ill more than 5 years ("no" $89.6 \%$, "yes" $75.9 \%, p=.003$ ).

- Work Engagement: Work experience $>5$ years ("no" $16.4 \%$, "yes" $36.0 \%, p<.001$ ), Age above 40 years ("no" $24.2 \%$, "yes" $43.9 \%, p=.001$ ), Work with terminally ill more than 5 years ("no" $24.0 \%$, "yes" $44.0 \%$, $p<.001)$.

- Work Engagement: Work experience $>5$ years ("no" $16.4 \%$, "yes" $36.0 \%, p<.001$ ), Age above 40 years ("no" 24.2\%, "yes" $43.9 \%, p=.001$ ), Work with terminally ill more than 5 years ("no" $24.0 \%$, "yes" $44.0 \%$, $p<.001)$. Compassion Satisfaction: Age above 40 years ("no" $75.8 \%$, "yes" $86.6 \%, p=.039$ ), Work with terminally ill more than 5 years ("no" $75.6 \%$, "yes" $86.9 \%, p=.030$ ).

There were no associations between Demographics and Burnout.

\subsection{Burnout vs. Work Engagement}

Table 2 shows that there was a mild negative correlation between the two scales (Spearman's rho $=-0.614, p<.001$ ). The prevalence rates of high burnout and low work engagement were $37.7 \%$ and $71.1 \%$ respectively, with $34.7 \%$ having both high burnout \& low work engagement (see Table 3).

Table 2. Correlation (Spearman's) between burnout, work engagement, compassion fatigue and compassion satisfaction

\begin{tabular}{llll}
\hline & $\begin{array}{l}\text { Compassion } \\
\text { Satisfaction }\end{array}$ & $\begin{array}{l}\text { Work } \\
\text { Engagement }\end{array}$ & $\begin{array}{l}\text { Compassion } \\
\text { Fatigue }\end{array}$ \\
\hline Burnout & $-0.700^{* * *}$ & $-0.614^{* *}$ & $0.503^{* *}$ \\
Compassion Satisfaction & & $0.772^{* *}$ & $-0.446^{* *}$ \\
Work Engagement & & & $-0.345^{* *}$ \\
\hline
\end{tabular}

${ }^{* *}$ Correlation is significant at the 0.01 level (2-tailed)

Table 3. Distribution of burnout and work engagement

\begin{tabular}{llll}
\hline Variable & \multicolumn{3}{l}{ Work Engagement } \\
\hline Burnout Category & Low $(<4)$ & High $(\geq 4)$ & Total \\
Low $(<17)$ & $2(0.6)$ & $9(2.7)$ & $11(3.3)$ \\
Moderate $(17-28)$ & $118(35.9)$ & $76(23.1)$ & $194(59.0)$ \\
High $(>28)$ & $114(34.7)$ & $10(3.0)$ & $124(37.7)$ \\
Total & $234(71.1)$ & $95(28.9)$ & $329(100)$ \\
\hline
\end{tabular}

Note. Values are $\mathrm{n}(\%)$. The percentages are of $\mathrm{n}=329$

Table 4 show that intrinsic factors that limits moderate/high burnout were BCS-Presence ( $\mathrm{OR}=0.28,95 \% \mathrm{CI} 0.09-0.9)$, GQ-6 (OR $=0.12,95 \% \mathrm{CI} 0.02-0.7)$ and GSE $(\mathrm{OR}=0.16$, $95 \%$ CI $0.05-0.46)$. No demographical variables were associated with this outcome. 
Table 4. Predictors for moderate/high burnout or low work engagement

\begin{tabular}{|c|c|c|c|c|c|c|}
\hline Measure & $\begin{array}{l}\text { Low Burnout }(\mathrm{n}=11) \\
\text { Mean }(S D)\end{array}$ & $\begin{array}{l}\text { Moderate/High } \\
\text { Burnout }(\mathrm{n}=318) \\
\text { Mean }(S D)\end{array}$ & $\begin{array}{l}\mathrm{OR}^{+} \\
(95 \% \mathrm{CI})\end{array}$ & $\begin{array}{l}\text { Low Work } \\
\text { Engagement }(n=234) \\
\text { Mean }(S D)\end{array}$ & $\begin{array}{l}\text { High Work } \\
\text { Engagement }(\mathrm{n}=95) \\
\text { Mean }(S D)\end{array}$ & $\begin{array}{l}\mathrm{OR}^{+} \\
(95 \% \mathrm{CI})\end{array}$ \\
\hline Ego Resiliency Total & $45.0(7.8)$ & $39.8(6.1)$ & $\begin{array}{l}0.5 \\
(0.2-1.2)\end{array}$ & $38.6(5.9)$ & $43.2(5.8)$ & $\begin{array}{l}0.45 \\
(0.32-0.63)^{*}\end{array}$ \\
\hline $\begin{array}{l}\text { General Self Efficacy } \\
\text { Total }\end{array}$ & $34.6(4.3)$ & $29.7(3.5)$ & $\begin{array}{l}0.16 \\
(0.05-0.46)^{*}\end{array}$ & $29.1(3.5)$ & 31.7 (3.5) & $\begin{array}{l}0.47 \\
(0.33-0.67)^{*}\end{array}$ \\
\hline GQ-6 Total & 39.5 (3.7) & $33.3(6.0)$ & $\begin{array}{l}0.12 \\
(0.02-0.70)^{*}\end{array}$ & $32.5(6.2)$ & $36.1(4.5)$ & $\begin{array}{l}0.62 \\
(0.43-0.87)^{*}\end{array}$ \\
\hline $\begin{array}{l}\text { Brief Calling-Presence } \\
\text { Total }\end{array}$ & $8.4(2.5)$ & $7.0(2.1)$ & $\begin{array}{l}0.28 \\
(0.09-0.90)^{*}\end{array}$ & $6.6(2.1)$ & $8.0(1.9)$ & $\begin{array}{l}0.45 \\
(0.32-0.65)^{*}\end{array}$ \\
\hline Brief Calling-Search Total & $3.4(2.2)$ & $5.0(2.3)$ & $\begin{array}{l}2.1 \\
(0.6-6.9)\end{array}$ & $5.3(2.2)$ & $4.2(2.3)$ & $\begin{array}{l}1.5 \\
(1.1-2.0)^{*}\end{array}$ \\
\hline
\end{tabular}

Odds Ratios adjusted for all Demographical variables in Table $1 ;{ }^{*} p<.05$

Table 4 also shows that all the intrinsic factors were associated with low work engagement. Limiting measures were BCS-Presence $(\mathrm{OR}=0.45,95 \%$ CI $0.32-0.65)$, GQ-6 $(\mathrm{OR}=0.62, \quad 95 \% \mathrm{CI} 0.43-0.87), \quad \mathrm{GSE}$ $(\mathrm{OR}=0.47,95 \% \mathrm{CI} 0.33-0.67)$ and ER89 $(\mathrm{OR}=0.45$, $95 \%$ CI $0.32-0.63)$. BCS-Search was positively correlated with low work engagement $(\mathrm{OR}=1.5,95 \% \mathrm{CI} 1.1-2.0)$. Work experience up to 5 years was also positively correlated with this outcome $(\mathrm{OR}=2.4,95 \% \mathrm{CI} 1.03-5.6)$.

Thus common intrinsic factors limiting both moderate/high burnout \& low work engagement were BCS-Presence, GQ-6 $\&$ GSE

\subsection{Compassion fatigue vs. Compassion satisfaction}

Table 2 show that there was a poor negative correlation between the two scales (Spearman's rho $=-0.446, p<.001$ ).

The prevalence rates of high compassion fatigue and low compassion satisfaction were $7.7 \%$ and $21.7 \%$ respectively, with $20.7 \%$ having both low compassion satisfaction and moderate/high compassion fatigue (see Table 5).

Table 5. Distribution of compassion fatigue and compassion satisfaction categories

\begin{tabular}{lllll}
\hline Variable & \multicolumn{4}{l}{ Compassion Satisfaction } \\
\hline Compassion Fatigue & $\begin{array}{l}\text { Low } \\
(<32)\end{array}$ & $\begin{array}{l}\text { Moderate } \\
(31-41)\end{array}$ & $\begin{array}{l}\text { High } \\
(>41)\end{array}$ & Total \\
Minimal & $2(0.6)$ & $0(0.0)$ & $3(0.9)$ & $5(1.5)$ \\
Some & $1(0.3)$ & $21(6.5)$ & $18(5.6)$ & $40(12.4)$ \\
Moderate & $56(17.3)$ & $158(48.9)$ & $39(12.1)$ & $253(78.3)$ \\
High & $11(3.4)$ & $13(4.0)$ & $1(0.3)$ & $25(7.7)$ \\
Total & $70(21.7)$ & $192(59.4)$ & $61(18.9)$ & $323(100)$ \\
\hline Note. Values are $\mathrm{n}(\%) ;$ The percentages are of $\mathrm{n}=323$ & &
\end{tabular}

Only the intrinsic factor BCS-Search was positively correlated with moderate/high compassion fatigue $(\mathrm{OR}=1.9$,
95\% CI 1.2 -3.0), with the "Chinese" race compared to the "Other" race being more at risk $(\mathrm{OR}=5.2,95 \% \mathrm{CI} 1.7-16.6)$ (see Table 5).

All the intrinsic factors were associated with low compassion satisfaction (see Table 6). Limiting measures were BCSPresence $(\mathrm{OR}=0.43,95 \% \mathrm{CI} 0.3-0.61)$, GQ-6 $(\mathrm{OR}=0.53$, $95 \% \mathrm{CI} 0.37-0.75)$ and $\mathrm{GSE}(\mathrm{OR}=0.60,95 \% \mathrm{CI} 0.42-0.86)$ and ER89 (OR $=0.56,95 \%$ CI $0.39-0.80)$. BCS-Search had a positive correlation $(\mathrm{OR}=2.1,95 \% \mathrm{CI} 1.4-3.1)$. Work experience with terminally ill up to 5 years was also positively correlated with this outcome (OR $=3.4,95 \% \mathrm{CI} 1.1-10.3)$.

Only BCS-Search drives moderate/high compassion fatigue $\&$ low compassion satisfaction.

\subsection{Correlation between Burnout \& Work Engagement with Compassion satisfaction \& Compassion fatigue}

There was a moderately strong (rho $>0.7$ ) correlation between compassion satisfaction with work engagement (rho $=0.772, p<.001)$ and with burnout (rho $=-0.700$, $p<.001$ ) but poor correlation for compassion fatigue with work engagement (rho $=-0.345) \& \mathrm{BO}($ rho $=0.503)$ (see Table 2).

\subsection{One factor (resilience) confirmatory factor analysis}

Table 7 shows the order of impact on Resilience of all the numerical-scale intrinsic variables (given by the standardized estimates) adjusted for demographical variables and factoring in all possible pairwise correlation between the intrinsic measures.

The top bundle of variables impacting Resilience was: BCSSearch, compassion satisfaction \& compassion fatigue, followed by the bundle of GQ-6, UWES \& burnout. GSE, ER89 $\&$ BCS-Presence had the least influence. 
Table 6. Predictors for high compassion fatigue or low compassion satisfaction

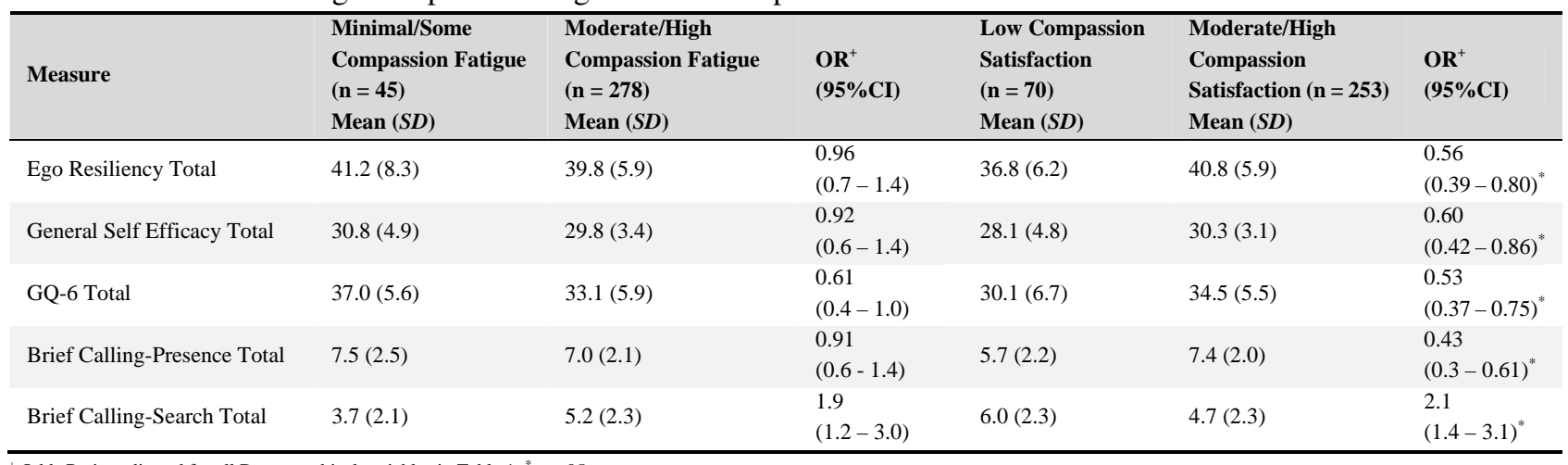

${ }^{+}$Odds Ratios adjusted for all Demographical variables in Table $1 ;{ }^{*} p<.05$

Table 7. Standardized estimates of the intrinsic measures on the latent variable: resilience

\begin{tabular}{llll}
\hline $\begin{array}{l}\text { Ranking (impact } \\
\text { on Resilience) }\end{array}$ & Variable & $\begin{array}{l}\text { Standardized Estimate } \\
(\mathbf{9 5} \% \mathbf{C I})\end{array}$ & p-value $^{*}$ \\
\hline 1 & BCS-S & $-0.367(-0.481,-0.253)$ & $<.001$ \\
2 & CS & $0.333(0.215,0.451)$ & $<.001$ \\
3 & CF & $-0.304(-0.423,-0.184)$ & $<.001$ \\
4 & GQ-6 & $0.244(0.121,0.367)$ & $<.001$ \\
5 & UWES & $0.261(0.139,0.383)$ & $<.001$ \\
6 & BO & $-0.229(-0.352,-0.106)$ & $<.001$ \\
7 & GSE & $0.140(0.013,0.266)$ & .031 \\
8 & ER89 & $0.087(-0.04,0.215)$ & .179 \\
9 & BCS-P & $0.040(-0.088,0.168)$ & .541 \\
\hline
\end{tabular}

*Adjusted for demographical variables in Table 1; Goodness of Fit Indices: Comparative Fit Index : CFI $=0.943$ (good fit $>0.9$ ); Standardized Root Mean Square Residual : SRMR $=0.047($ good fit $<0 ; .08)$; Root Mean square Error of Approximation : RMSEA $=0.063$ (good fit $<0.06)$

\section{Discussion}

Past research in the area of burnout and compassion fatigue among doctors has focused mainly on those working in oncology, palliative care and general practitioners which showed high prevalence rates of burnout and compassion fatigue. Our study found that $37 \%$ of the doctors were at high risk of burnout and $7.5 \%$ were at high risk of compassion fatigue. Although this is comparable to current findings, we also found that only $3.3 \%$ and $1.5 \%$ were at low risk of burnout and compassion fatigue respectively, which is significantly lower than those reported in other studies. ${ }^{[10,39,40]}$ In addition, there was no statistically significant difference between burnout and compassion fatigue rates across the various medical and surgical specialities including oncology and palliative care. This means that doctors of any discipline are at equal risk of burnout and compassion fatigue. In our study, the rates of high work engagement and high compassion satisfaction were also noted to be extremely low; $2.7 \%$ and $0.3 \%$ respectively.

Our study results also show that burnout and work engage- ment, and, compassion satisfaction and compassion fatigue are negatively related and hence likely opposite dimensions of each other. This means that any effort at enhancing work engagement and compassion satisfaction may help to mitigate the risk of burnout and compassion fatigue respectively. To our knowledge, the preliminary evidence from our study is the first to show that intrinsic human factors, rather than extrinsic/environmental factors such as age, gender, seniority, number of working hours and years of experience, are more significantly related to burnout, work engagement, compassion satisfaction and compassion fatigue among doctors. Interestingly, all the intrinsic factors selected in this study positively impacted work engagement and compassion satisfaction but not burnout and compassion fatigue. This suggests that burnout, work engagement, compassion fatigue and compassion satisfaction may be distinct concepts since intrinsic factors that buffer one may not do so entirely with the other. Our findings support the views of Schaufeli and Bakker. ${ }^{[41]}$ Hence more research in this area is needed to better define each of these concepts in order to better understand their individual aetiologies.

The intrinsic human factors chosen for our study had been previously shown to contribute to subjective well-being or happiness, and, subjective well-being has been shown to positively impact psychological adjustment and adaptation. ${ }^{[42]}$ In his book "Authentic Happiness", Seligman ${ }^{[43]}$ posited that emotional well-being comes from engaging in personal signature strengths. He defined signature strengths as "positive characteristics that recur across time and different situations that bring about good feelings and gratification". Unlike talent which is something that an individual is born with, strengths can be acquired. Thus acquiring certain signature strengths can not only help buffer against negative emotion and challenging life circumstances but also lead to a meaningful life when used in the context of something larger than oneself. As these intrinsic factors can be acquired, develop- 
ing training programs or positive psychology interventions that specifically focus on the building of the doctor's perceived self-efficacy, a sense of gratitude and a work calling may enhance personal resilience against burnout and compassion fatigue and increase work engagement and compassion satisfaction.

There are some limitations to our study. The participants were a convenience sample and did not include all the medical and surgical disciplines within the acute hospital although we targeted the largest departments within each discipline. Majority of the surveys were done at department meetings where the objectives of the study were highlighted and this could have incurred responder bias to the questionnaires. Although we included some of the commonly reported demographic factors that influence burnout, work engagement, compassion satisfaction and compassion fatigue, we did not include others like workload, control over work schedule, demanding patients and work-life conflicts. To our knowledge, the scales used in this study have not been validated locally even though they have been used in previous research. However we did perform Cronbach's alphas for all the scales used and found them consistent with that previously reported; ranging from 0.786 to 0.907 .

\section{Practical implications}

Our preliminary findings suggest that certain intrinsic human factors increase work engagement and compassion satisfaction amongst doctors. As some of these intrinsic human factors also appear to buffer against burnout and compassion fatigue, increasing work engagement and compassion satisfaction could not only build individual resilience against burnout and compassion fatigue but may also lead to improvement in overall health, professional quality of life and career longevity for doctors. These findings have important implications for healthcare institutions. Apart from continuing to improve the extrinsic antecedent factors within the healthcare system, hospitals should also consider investing in physician wellness programs that improve competencies in psychological and emotional recovery as a result of workplace stress and crises, individual as well as group well-being and optimal functioning through developing positive individual strengths/traits and positive experiences. Any program, whether individual or group, targeting burnout and compassion fatigue should have measurable components that positively impact on improving the sense of self-efficacy, gratitude, optimism and life satisfaction that leads to increasing conviction of sense of calling to their choice of career.

Currently some of such programs include crisis intervention courses, ${ }^{[44]}$ mental health first aid courses and Ballint groups. ${ }^{[45]}$ Professional coaching that apply techniques from the field of positive psychology have also been found to be very useful in improving physician quality of life through strategies that increase self-awareness, aligning personal values with professional duties, focusing on strengths, questioning thought patterns and beliefs as well as providing a supportive sounding board and partnership. ${ }^{[46]}$

\section{Conclusions}

Healthcare in Singapore faces a chronic manpower shortage. Retaining talented doctors and ensuring that they consistently deliver care of a high standard in a sustainable way is a constant challenge facing all healthcare services. As the environmental conditions in healthcare are likely to remain unchanged due to the nature of the work, changing the way each individual doctor perceives his/her role through strategies that enhance personal resilience is likely to be a more feasible and logical strategy.

\section{ACKNOWLEDGEMENTS}

We would like to thank all the doctors of Changi General Hospital and National Cancer Centre for their invaluable support in this study.

\section{REFERENCES}

[1] Boudreau RA, Grieco RL, Cahoon SL, et al. The pandemic from within: two surveys of physician burnout in Canada. Can J Commun Mental Health. 2006; 25(2): 941-947. http://dx.doi.org/10. 7870/cj cmh-2006-0014

[2] Koh MYH, Poh HC, Neo PSH, et al. Burnout, psychological morbidity and use of coping mechanisms among palliative care practitioners: a multi-centre cross sectional study. Palliative Med. 2015; 1-10. http://dx.doi.org/10.1177/0269216315575850

[3] Chan AOM, Chan YH. Influence of work environment on emotional health in a healthcare setting. Occupational Med. 2004; 54: 207-212. http://dx.doi.org/10.1093/occmed/kqh062

[4] Braun M, Sconfeldt-Lecuona C, Freudenmann R, et al. Burnout, depression and substance abuse in physicians-An overview of actual data in Germany. Psychoneuro. 2007; 33: 19-22. http://dx. doi . org/10.1055/s-2007-973732

[5] Thomas NK. Resident burnout. JAMA. 2004; 292: 2880-2889. PMid: 15598920. http://dx.doi.org/10.1001/jama.292.23.2880

[6] Balch CM, Freischlag JA, Shanafelt TD. Stress and burnout among surgeons: Understanding and managing the syndrome and avoiding the adverse consequences. Arch Surg. 2009; 144: 371-376. PMid: 19380652. http://dx.doi.org/10.1001/archsurg. 20 08.575

[7] Lin YW. The causes, consequences and mediating effects of job

Published by Sciedu Press 
burnout among hospital employees in Taiwan. J Hospital Administration. $2013 ; 2(1)$ : 15-27.

[8] El-bar N, Levy A, Wald HS, et al. Compassion fatigue, burnout and compassion satisfaction among family physicians in the Negev area-a cross sectional study. Israel J Health Policy Research. 2013; 2: 31-38. PMid: 23947591. http://dx.doi .org/10.1186/2045-4015-2 $-31$

[9] Schaufeli WB, Maassen GH, Bakker AB, et al. Stability and change in burnout: A 10-year follow-up study among primary care physicians. J Occupational and Organizational Psychology. 2011; 84(2): 248-267. http://dx.doi.org/10.1111/j.2044-8325. $2010.02013 . \mathrm{x}$

[10] Maslach C, Schaufeli WB, Leiter MP. Job burnout. Ann Rev Psychol. 2001; 52: 397-422. PMid: 11148311. http://dx.doi.org/10.11 46/annurev.psych.52.1.397

[11] Miller N, McGowen R. The painful truth: physicians are not invincible. South Med J. 2000; 93(10): 966-73. PMid: 11147478. http://dx.doi.org/10.1097/00007611-200093100-00004

[12] Spickard A Jr, Gabbe SG, Chrisensen JF. Mid-career burnout in generalist and specialist physicians. JAMA. 2002; 288(12): 1447-50. http://dx.doi.org/10.1001/jama.288.12.1447

[13] Maslach C, Leiter MP. The truth about burnout: How organizations cause personal stress and what to do about it. San Francisco, CA Jossey-Bass; 1997. PMid: 9332965.

[14] Schaufeli WB, Bakker AB. Job demands, job resources and their relationship with burnout and engagement: a multi-sample study. J of Organizational Behavior. 2004; 25: 293-315. http://dx .doi .o rg/10.1002/job. 248

[15] Schaufeli WB, Enzmann D. The burnout companion to study and practice: a critical analysis. London: Taylor \& Francis; 1998.

[16] Shirom A, Meamed S, Toker S, et al. Burnout and health review current knowledge and future research directions. Int Rev Ind Organ Psychol. 2005; 20: 269-307. http://dx.doi.org/10.1002/047 $0029307 . \operatorname{ch} 7$

[17] Soonentag S, Mojza EJ, Demerouti E, et al. Reciprocal relations between recovery and work engagement: the moderating role of job stressors. J Appl Psychology. 2012; 97: 842-853. PMid: 22545619. http://dx.doi.org/10.1037/a0028292

[18] Bakker AB, Demerouti E, Verbeke W. Using the job demandsresources model to predict burnout and performance. Hum Resource Manag. 2004; 43: 83-104. http://dx.doi.org/10.1002/hrm.2 0004

[19] Xanthopoulou D, Bakker AB, Demerouti E, et al. Work engagement and financial returns: a diary study on the toll of job and personal resources. J Occup Organ Psychol. 2009; 82: 183-200. http://dx.doi.org/10.1348/096317908X285633

[20] Winefield HR. Work stress and its effects in General Practitioners. In M.F. Dollard, A.H Winefield \& H.R Winefield (Eds), Occupational stress in the service professions (pp 191-212). London: Taylor \& Francis; 2003. http://dx.doi.org/10.1201/9780203422809 . $\operatorname{ch} 7$

[21] Wallace JE, Lemaire JB, Ghali WA. Physician wellness: a missing quality indicator. Lancet. 2009; 374 (9702): 1714-1721. http: //dx.doi.org/10.1016/S0140-6736(09)61424-0

[22] Joinson C. Coping with compassion fatigue. Nursing. 1992; 22: 116-122. PMid: 1570090. http://dx.doi.org/10.1097/00152 193-199204000-00035

[23] Huggard P. Secondary traumatic stress doctors at risk. New Ethical J. 2005; 6(9): 9-14.

[24] Kleber RJ, Figley CR. Beyond the 'victim': secondary traumatic stress. In Beyond Trauma: cultural and societal dynamics (pp 75-98).
Edited by Kleber JR, Figley CR, Gersons BPR. New York: Plenum; 1995. http://dx.doi.org/10.1007/978-1-4757-9421-2

[25] Stamm BH. ProQOL Manual. Lutherville: Sidran Press; 2005.

[26] Collins S, Long A. Working with the psychological effects of trauma: consequences for mental health-care workers - a literature review. J Psychiatric and Mental Health Nursing. 2003; 10(4): 417-424. http://dx.doi.org/10.1046/j.1365-2850.2003.00620.x

[27] Mathieu F. The compassion fatigue workbook. New York: Routledge Taylor \& Francis Group; 2012.

[28] Zwack J, Schweitzer J. If every fifth physician is affected by burnout, what about the other four? Resilience strategies of experienced physicians. Academic Medicine. 2013; 88(3): 382-389. PMid: 23348093. http://dx.doi.org/10.1097/ACM. Ob013e318281696b

[29] Alarcon G, Eschleman KJ, Bowling NA. Relationships between personality variables and burnout: a meta-analysis. Work Stress. 2009; 23: 244-263. http://dx.doi .org/10.1080/026783709032826 00

[30] Schaulfeli WB, Bakker AB, Salanova M. The measurement of work engagement using a short questionnaire: A cross-national study. Educational and Psychological Measurement. 2006; 66(4): 701-716. http://dx.doi.org/10.1177/0013164405282471

[31] Danielli Y. Psychotherapists' participation in the conspiracy of silence about the Holocaust. Psychoanalytic Psychology. 1984; 1: $23-$ 42. http://dx.doi.org/10.1037/0736-9735.1.1.23

[32] Baranowsky AB. The silencing response in clinical practice: on the road to dialogue, In CR Figley (ed), Treating compassion fatigue (pp 155-170). New York: Brunner-Routledge; 2002.

[33] Luszczynska A, Gutierrez-Dona B, Schwarzer R. General selfefficacy in various domains of human functioning: Evidence from five countries. International J of Psychology. 2005; 40(2): 80-89. http://dx.doi.org/10.1080/00207590444000041

[34] Block JH, Kremen AM. IQ and ego-resiliency: Conceptual and empirical connections and separateness. J Personality and Social Psychology. 1996; 70: 349-361. http://dx.doi.org/10.1037/0 $022-3514.70 \cdot 2.349$

[35] Letziring T, Block J, Funder D. Ego-control and ego-resiliency: Generalization of self-report scales based on personality description from acquaintances, clinicians and the self. $\mathrm{J}$ of Research in Personality. 2004; 39: 395-422. http://dx.doi.org/10.1016/j.jrp. 2004. 06.003

[36] McCullough ME, Emmons RA, Tsang J. The Grateful Disposition: A conceptual and Empirical Topography. Journal of Personality and Social Psychology. 2002; 82: 112-127. PMid: 11811629. http://dx.doi.org/10.1037/0022-3514.82.1.112

[37] Dik BJ, Steger MF. Work as a Calling: Randomized trial of a callingbased career development workshop. Paper presented at the National Career Development Association Global Conference Jul, Chicago, IL; 2006.

[38] Dik BJ, Sargent AM, Steger MF. Career development strivings: assessing goals and motivation in career decision-making and planning. J of Career Development. 2008; 35: 23-41. http://dx . doi . org/1 $0.1177 / 0894845308317934$

[39] Gleichgerrcht E, Decety J. The relationship between different facets of empathy, pain perception and compassion fatigue among physicians. Frontiers in Behavioral Neuroscience. 2014; 8: 243-251. http://dx.doi.org/10.3389/fnbeh.2014.00243

[40] Bellolio MF, Cabrera D, Sadosty AT, et al. Compassion fatigue is similar in emergency medicine residents compared to other medical and surgical specialities. Western J of Emerg Med. 2014; 15(6): 629-35. PMid: 25247031. http://dx.doi.org/10.5811/westj em.2014.5.21624 
[41] Schaufeli WB, Bakker AB. UWES-Utrecht Work Engagement Scale: Test Manual. Utrecht, The Netherlands: Department of Psychology, Utrecht University; 2003.

[42] Lyubomirsky S, King L, Diener E. The benefits of frequent positive affect: Does it lead to success? Psychological Bulletin. 2005; 131: 803-855. PMid: 16351326. http://dx.doi.org/10.1037/003 $3-2909.131 .6 .803$

[43] Seligman MEP. Authentic Happiness. New York, USA: Free Press; 2002.
[44] Chan AOM, Chan YH, Kee PC. Improving resistance and resiliency through crisis intervention training. Int J Emerg Mental Health. 2012; 14(2): 77-86. PMid: 23350223.

[45] Kjeldmand D, Holmstrom I. Ballint groups as a means to increase job satisfaction and prevent burnout among general practitioners. Ann Fam Med. 2008; 6: 138-145. PMid: 18332406. http://dx.doi.org/10.1370/afm.813

[46] Gazelle G, Liebschutz JM, Riess H. Physician burnout: coaching a way out. J Gen Intern Med. 2014. http://dx. doi .org/10.1007 /s11606-014-3144-y 